\title{
BRUNO DE MENEZES E LÉOPOLD SÉDAR SENGHOR: POÉTICA, NEGRITUDE E RELIGIOSIDADE
}

\author{
Mariana Janaina dos Santos ALVES
}

\begin{abstract}
RESUMO
O artigo apresenta reflexões críticas e algumas considerações teóricas sobre os aspectos de religiosidade e da negritude contidos no poema Toiá Verequête, retirado do livro Batuque de Bruno de Menezes. O poema analisado foi publicado, pela primeira vez, em 1931. Sabemos que Batuque, ao longo do século passado, recebeu várias edições, dentre elas, citamos algumas, como a de 1966, 1984, 1993 e 2005. A obra, ao nosso ver, é uma das mais importantes da expressão poética moderna na Amazônia. E, Bruno de Menezes membro de destaque da Academia do Peixe Frito, é um escritor fundamental deste periodo, pois, ele apresenta em seus livros uma abordagem inovadora da lírica do norte do Brasil. Essa marca se faz presente com usos particulares da linguagem, personagens marcadas pela cor local, cenas do cotidiano popular, além da escrita registrada pela musicalidade, o ritmo, a religiosidade e a festa. Por esse motivo, escolhemos para esta análise, um poema retirado da edição especial comemorativa que foi lançada em Belém, no ano de 1966. Assim, o artigo, que ora se apresenta, discorre sobre a religiosidade, o misticismo e a negritude no poema citado aliando os postulados da literatura, aos estudos culturais e antropológicos, como vieses complementares. Os autores escolhidos nessas perspectivas teóricas foram Bosi (2010), Ferretti (1996/1997) e Ribeiro (1995). Destarte, para comparar a poética meneziana vista sob os aspectos da negritude, citamos elementarmente outro autor, desta vez, oriundo da literatura moderna francófona, o intelectual Léopold Sédar Senghor. Destacamos, por fim, que o artigo se compõe a partir dos estudos realizados em tese de doutorado, pesquisa que se encontra em andamento, intitulada Tradução Cultural, Intersemiótica e Négritude nos poemas de Bruno de Menezes de Léopold Sédar Senghor: Modernismo na obra Batuque e Éthiopiques, desenvolvida na Universidade Estadual Paulista- UNESP.
\end{abstract}

Palavras-chave: Poética; Negritude; Religiosidade; Modernismo.

\begin{abstract}
RÉSUMÉ
Cet article présente les réflexions critiques, puis, quelques considérations théoriques sur les aspects de la religiosité et de la négritude dans le poème Toiá Verequête, choisi du livre Batuque de Bruno de Menezes. Le poème pris pour faire l'analyse, il a été publié, la première fois, en 1931. On sait que Batuque, tout au long du siècle dernier, il a reçu plusieurs éditions, parmi elles, on cite celles-ci : celle de 1966, 1984, 1993 et 2005. L'œuvre, à notre regard, est l'une de plus importante de l'expression poetique moderne de l'Amazonie. Puis, Bruno de Menezes, membre illustre de l'Académie du Poisson Frit, lui, il est un écrivain fondamental dans cette période, car, il présente dans ces livres une approche d'innovation de la lyrique faite au nord du Brésil. Cette marque se fait présente avec l'usage particulière du langage, personnages touchés par la couleur local, scènes du quotidien populaire, ailleurs de l'écriture enregistrée par la musicalité, le rythme, la religiosité et la fête. Pour ce motif, on a choisi pour cette analyse, un poème pris d'édition spéciale commémorative celle qui a été mise en place à Belém, en 1966. Ainsi, l'article, que se présente maintenant, il s'agit de la religiosité, du mysticisme et la négritude dans le poème mentionné en y ajoutant les postulats de la littérature, les études culturelles et anthropologiques, tels que des études complémentaires. Les auteurs qu'on a choisi dans ces perspectives théoriques étaient Bosi (2010), Ferretti (1996/1997) et Ribeiro (1995). Ainsi, pour comparer la poétique de Menezes à partir des aspects de la négritude, on cite notamment l'autre auteur, cette fois-ci, qui appartient à la littérature moderne francophone, l'intellectuel Léopold Sédar Senghor. On souligne, à la fin que, cet article se compose à partir des études suivies dans la thèse de doctorat, recherche qu'on se développe encore, intitulé Traduction culturelle, intersemiotique et Négritude dans les poèmes de Bruno de Menezes et Léopold Sédar Senghor: Modernisme dans l'œuvre Batuque et Éthiopiques, développée à l'Université de l'État à São Paulo - UNESP.
\end{abstract}

Mots-Clés: Poétique ; Négritude ; Religiosité ; Modernisme.
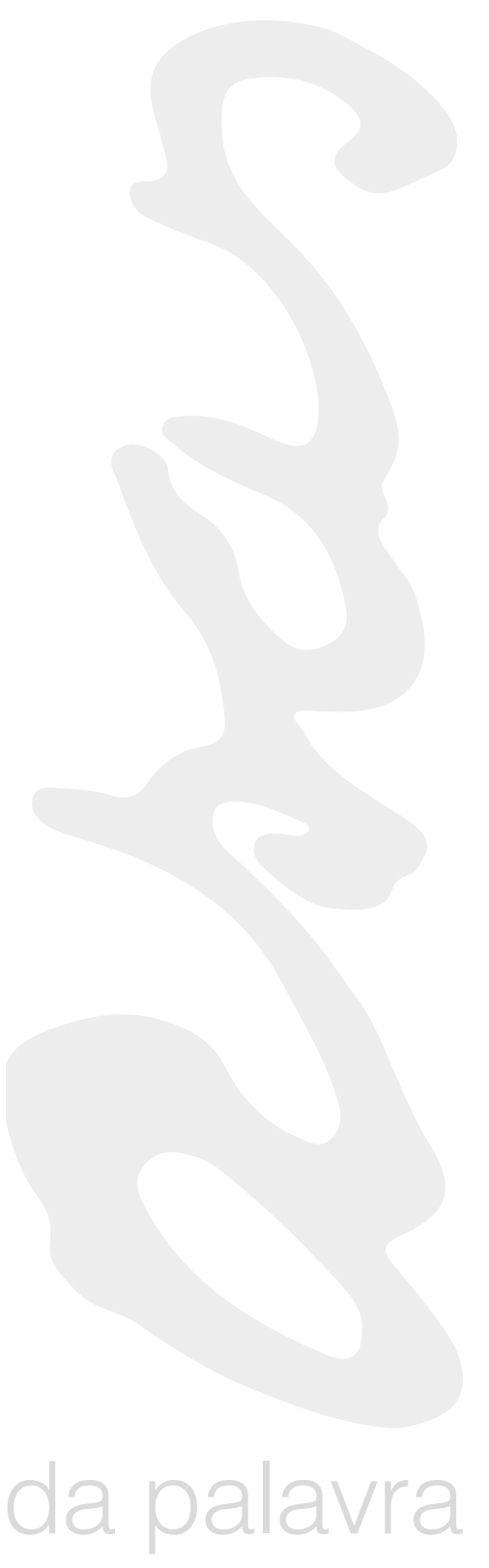

\begin{tabular}{l|l|ll} 
VOL. 15 & N. 1 & JUL. 2018
\end{tabular}

ISSN 1415-7950 


\section{INTRODUÇ̃̃O}

A obra Batuque, publicada pela primeira vez em 1931, de Bento Bruno de Menezes, é marco da expressão poética na literatura popular do Pará. O livro, produzido no início do século XX, registrou na escrita dos autores do norte do país, uma criação literária que se compara aquela assinada por outros escritores que escreveram sob a ótica da periferia moderna, e que compuseram, por exemplo, um cenário multicultural na literatura mundial.

Nesse contexto, de autores que escreveram no âmbito da perspectiva dos vencidos, para lembrar o termo alcunhado por Michel Lowy (2010), destacamos especialmente, os autores, hoje, conhecidos no cenário da literatura francófona, aquela que é escrita em língua francesa, por escritores que não são necessariamente nascidos na França, mas que utilizaram a língua francesa como forma de expressão literária e cultural. Consideramos, nesse sentido, como destaque para este artigo, os representantes do movimento da Négritude, sendo eles, Léopold Sédar Senghor, Léon Gontran-Damas e Aimé Césaire.

Sabe-se que Bruno de Menezes é escritor determinante no contexto do modernismo da Amazônia, e que sua obra foi louvada e reconhecida por outros escritores e críticos na época em que os livros foram publicados. Há, inclusive, menção ao poeta em uma das revistas mais atuantes do movimento da Négritude dos anos 1930: a revista Présence Africaine. Essa informação pode ser confirmada na apresentação da $6^{\mathrm{a}}$ edição de Batuque (1984) escrita pela presidente do Conselho Estadual de Cultura do Pará e no prefácio da $7^{\mathrm{a}}$ edição (2005) escrito por Josse Fares e Paulo Nunes. No primeiro texto mencionado, Maria Annunciada Chaves reitera a importância da obra para o modernismo brasileiro e alude à citação feita ao poeta, Bruno de Menezes, na revista citada, em maio de 1960. No artigo publicado em Paris, segundo as palavras de Chaves na apresentação, a obra é considerada "uma coleção de imagens vivamente coloridas, estuantes de sabor popular", porém impregnadas de "uma atmosfera sagrada e mística" (MENEZES, 1984, p.11).

A obra Batuque se inscreve no estilo moderno e tornou-se uma das mais célebres pinturas da literatura de periferia brasileira, assim como, uma das principais obras literárias produzidas no norte do Brasil.

Os poemas apresentam, em sua composição lírica, a temática da negritude, que inclusive, também foi utilizada como fonte para a criação poética de outros autores contemporâneos a Menezes, conforme mencionado anteriormente, escritores que marcaram a produção em literatura francófona do início do século. Contudo, não se sabe ao certo, se Menezes teve acesso a literatura de Senghor, Damas ou Césaire. Mas, o que se pode afirmar é que os poemas desses autores foram escritos e publicados em língua francesa, que eles pertencem ao estilo poético da literatura moderna e eram pessoas engajadas política e socialmente em seus países de origem. Além dessas características, consideradas essenciais para a compreensão das obras que constituem a produção literária oriunda da Négritude, esses escritores pertenciam a um cenário da periferia colonizada pelos europeus em países da África e ex-colônias francesas. Esse grupo, liderado por Léopold Sédar Senghor apresentou ao mundo o movimento intelectual, e até o momento, são autores que ainda não foram traduzidos para a língua portuguesa.

Dadas essas constatações, não se pode afirmar precisamente se Bruno de Menezes teve acesso a produção da Négritude, ou, ainda, se os autores do movimento tiveram acesso a obra Batuque. Mas, ao que indica a citação feita por Chaves na apresentação do livro escrita em 1984, é que em algum momento, os escritores tiveram conhecimento do que se elevava, em termos literários, na Amazônia, na primeira metade do século passado.

Consideramos, pois, que a obra de Bruno de Menezes, independentemente de ter ou não relação com aquelas, da literatura francófona, feitas fora do eixo canônico europeu, que a primeira significa, de fato, a reivindicação de autores modernos, principalmente no contexto da Amazônia brasileira e que em alguns pontos, coincide com o que foi feito por escritores que compunham sob a égide da Négritude. 
Entre os autores, destacamos, Dalcídio Jurandir, Raul Bopp e Bruno de Menezes por terem publicado obras que expõem questões da sociedade da época, do cenário moderno, da periferia, utilizando-se de personagens (seja na prosa ou na poesia) que representavam pessoas comuns, trabalhadores, mulheres, que estavam, de certa maneira, fora de um contexto elitista e de uma sociedade capitalista bem sucedida.

$\mathrm{Na}$ Academia do Peixe Frito, Bruno de Menezes participava dessa reunião ao ar livre, que recebia diferentes epítetos, conforme a ocasião. No momento em que se reuniam no Ver-o-Peso, era a Academia Peixe-Frito. Eram encontros regados a aperitivos e, como tira-gosto, peixe frito. Em outras situações diziam ser Vândalos do Apocalipse por talvez estarem discutindo e anunciando a poética dos novos tempos. Tempos depois organizaram a Associação dos Novos para divulgar as novas ideias (PACHECO, 2003, p.167).

As obras produzidas, por estes e outros autores da Academia do Peixe Frito, demonstravam abordagens diversas sobre temas que versavam sobre a religião, as crenças populares e às questões de etnicidade. Sobre estas últimas, de acordo com as palavras de Darcy Ribeiro, entende-se que essa massa de nativos oriundos da mestiçagem viveu por séculos sem consciência de si, afundada na runguendade. Assim foi até se definir como uma nova identidade étnico nacional, a de brasileiros. Um povo, até hoje, em ser, na dura busca de seu destino. Olhando-os, ouvindo-os, é fácil perceber que são, de fato, uma nova romanidade, uma romanidade tardia mas melhor, porque lavada em sangue índio e sangue negro (1995, p.453). Desta forma, os autores apresentavam nos textos, naturalmente, a interpretação sobre as discussões étnicas, tão presentes no cotidiano, na cultura e na vivência destes escritores.

Assim, fora do eixo Rio de Janeiro e São Paulo, no qual, se encontrava a cena moderna brasileira e os atores que compuseram a Semana de Arte de 1922, foram inscritos personagens essenciais que simbolizam figuras elementares do povo amazônico, registrando assim, a presença do Modernismo, no outro eixo do Brasil, no norte do país. Nesse contexto, encontra-se a expressividade de escritores que não compunham, necessariamente, a elite apresentada da cena moderna de 1922, tão referenciada pela crítica literária brasileira, mas sim, a amazônica feita a partir da perspectiva de autores locais, em sua maioria, escritores originários da periferia, que tratavam em termos universais temas da cultura popular, da identidade, da raça, de uma sociedade recém liberta e republicana.

Os autores nortistas, os quais, consideramos a produção literária como integrante da expressão moderna no Brasil, principalmente aqueles que produziram no início do século passado, entre eles, Bruno de Menezes, receberam nos últimos anos, maior atenção no que se refere às pesquisas feitas no âmbito da crítica literária, em todo o país. Estudos realizados recentemente, tais como, feitos em programas de pós-graduação na área de humanidades, em todo país, tem debatido a consolidação da geração moderna do norte do Brasil, de forma tão relevante e integrada ao modernismo brasileiro, quanto aquela da Pauliceia Desvairada.

\section{NÉGRITUDE E POÉTICA: CONSIDERAÇÕES INTRODUTÓRIAS}

O conceito de Négritude tomado como referência para este artigo é o que se delineia a partir da crítica de János Riesz, no qual, o autor afirma que o ponto de partida desse movimento foi a escrita de Senghor e as proposições elencadas pelo poeta senegalês, em 1952, que refletiam as múltiplas faces da cultura dos negros, sobretudo, os que habitavam nos territórios colonizados, assim como, o discurso assinalava questões sobre cidadania e raça, como se pode ler no trecho que segue:

Mettez-vous dans leur peau, réveillez-vous, un matin, noirs et colonisés, noirs et nus, dans le «(saisissement d'être vus») par le regard corrosif du Blanc. Ils savaient, ces étudiants nègres d'entre les années 25 à 35, que l'Europe, depuis trois siècles, avait enseigné à leurs pères leur néant - aux esclaves, aux «sujets》 comme aux citoyens de 1849. Ils n'avaient pas de patrimoine: ils n'avaient rien pensé, rien bâti, rien peint, rien chanté. Ils étaient néant, au fond de l'abîme, dans
1 Coloquem-se na sua pele, despertem, um dia, negros e colonizados, negros e nus, no "choque profundo de ser visto" pelo olhar corrosivo do Branco. Eles sabem, estes estudantes negros, d'entre os anos de 25 à 35 , que a Europa, há três séculos, tinha ensinado aos seus pais, o nada deles - aos escravos, aos "sujeitos" como aos cidadãos de 1849. Eles não tinham patrimônio: Eles não tinham nada pensado, nada construído, nada pintado, nada cantado. Eles eram nada, o fundo do abismo, no absoluto do desespero. Porque, como tirar nada de nada? (Tradução nossa). 
No trecho acima, compreende-se que Senghor propõe que os negros coloquem-se em sua própria pele, e que despertem, um dia, colonizados, negros e nus, na "tentativa de serem vistos" pelo olhar corrosivo do Branco. No contexto, o poeta refere-se aos estudantes negros que entre os anos de 1925 a 1935, estudaram na Europa, neste mesmo território que há três séculos, ensinava os pais deles a se tornarem escravos, tratava-os como "sujeitos", mas, que os consideravam como cidadãos desde 1849. Essas pessoas, naturalmente, seus antepassados, não tinham patrimônio: que dizer, no sentido cultural; intelectual, pois, nada tinham para pensar, uma vez que eles não possuíam referências, em termos artísticos, como se pode ler no trecho final da citação: nada de nada. Os aspectos que ficavam de herança era o fundo do abismo, o absoluto desespero.

Sabe-se que as questões postuladas por Senghor ergueram-se como bandeira e serviram de pano de fundo nas obras que integraram o movimento da Négritude, que a partir dos anos de 1930 se concretizou com uma ampla produção artística, em vários territórios que foram colonizados no mundo. Esse grupo de intelectuais, que em sua maioria, veio dos territórios para estudar na Sorbonne em Paris, desenvolvia-se não apenas versando sobre política, em seus vários aspectos, mas também, consolidando escritores em âmbito nacional, que escreveram em língua francesa, para que seus ideais fossem compartilhados, e assim, elencar por meio das artes, as discussões que envolvem as diferenças entre os seres humanos.

Os autores da Négritude, na maior parte, escreviam sobre a valorização da identidade de cada povo, da cultura como patrimônio, e também, sobre assuntos nem sempre tão agradáveis e que restaram como heranças negativas do processo colonizador, por exemplo, as pessoas que se encontram à margem da sociedade, que sofrem racismo e são subjugados pelo preconceito. Outros temas surgem nas obras artísticas, sobretudo, na literatura para a valorização da cultura de origem africana. $\mathrm{O}$ uso das línguas de cada povo, os dialetos falados em determinadas regiões do território africano, o belo sob a perspectivismo do negro - principalmente no que se refere a natureza - e o misticismo são tomados como ponto de partida, mas dessa vez, para a intensificação do uso desses elementos como catalisadores da cultura não europeia, diferente da que foi instituída como hegemônica. Trata-se de assinalar o diverso para transformar o pensamento que foi instituído, ao longo dos séculos, em relação ao negro.

Assim, os poetas da Négritude, ao nosso ver, e com base nos pressupostos de Alfredo Bosi, valem-se da linguagem da poesia que, por sua vez, é mais singularizadora que a da não-poesia. A existência, enquanto ainda não repartida e limitada pela divisão do trabalho mental que produz o código das ideias abstratas, apresenta-se na sua variadíssima concreção de aspectos, formais, sons, cores. A palavra poética recebe uma espécie de efeito mágico do seu convívio estreito com o modo singular, pré-categorial, de ser de qualquer um desses aspectos. Singular não quer dizer isolado. O objeto separado é um dado empírico, igual a todos os outros dados empíricos, e assim tratado pela ciência positivista que o destaca da percepção singularizadora [...]. No poema, o singular é o concreto, o ser multiplamente determinado, multiplamente unido aos sentimentos e aos ritmos da experiência, multiplamente composto de conotações históricas e sociais (2010, p. 132-133).

Compreende-se assim, que a poesia em seu uso, tanto como elemento transformador da sociedade, quanto por meio de fruição intelectual, vale-se da sensibilização e do uso sensorial de suas faculdades para permitir que tanto o poeta, quanto o leitor, ambos, possam compartilhar desta experiência individual e alinear.

$\mathrm{O}$ aspecto concreto do poema cresce nas fibras espessas da palavra, que é um código sonoro e temporal; logo, um código de signos cujos referentes não transparecem, de pronto, à visão. Para compensar esse intervalo, próprio de toda atividade verbal, o poema se faz fortemente motivado na sua estrutura fonética, na sintaxe e no jogo das figuras semânticas $(2010$, p. 134). A palavra poética permanece. A ex- 
pelo tempo.

Assim, o papel fundamental dos criadores de poesia está vinculado a necessidade de tornar o mundo em que se vive sensível às questões humanas, ao caráter imanente da vida e ao que está oculto nas formas do desconhecido ou silenciado pelo tempo e nas formas de dominação, sejam elas, intelectuais, religiosas, políticas ou de poder.

\section{RELIGIOSIDADE: TAMBOR DE MINA EM TOIÁ VEREQUÊTE}

Para Denis Bertrand a literatura exerce pois, por natureza, uma função crítica sobre a língua, desaprumando-a em relação a si mesma em cada obra. No âmbito da cultura, a literatura é esse imenso reservatório da memória coletiva, canteiro em que ela se elabora com os materiais que dispõe, arquivo em que ela se fixa e se institui como referência cultural (2003. p. 25). Com base nesses pressupostos, entendemos que a literatura atua como um meio de transmissão de conteúdos míticos e axiológicos, das maneiras de ser e fazer de uma comunidade, e nela, se depositam e se transformam tanto modelos de ação, quanto de representação.

Nesse sentido, para melhor compreender os caminhos propostos pela poética e a singularidade da obra meneziana e os aspectos da negritude nela contidos, escolheu-se um poema que apresenta, no âmbito semântico literário, a religiosidade a partir de rituais de matriz africana, práticas ancestrais e o misticismo. Ei-lo:

Toiá Verequête

A voz de Ambrosina em "estado de santo" virou masculina.

O corpo tomou jeitão de homem mesmo.

Pediu um charuto dos puros Bahia

depois acendeu soprando a fumaça;

Seus olhos brilharam.

Ai o "terreiro" num gira girando

entrou na tirada cantada do "ponto".

Era a "obrigação" de Mãe ambrosina

falando quimbundo na língua de Mina.

"Toiá Verequête!"

"Toiá Verequête!"

O santo dos pretos o São Benedito tomou logo conta de mãe Ambrosina fez do corpo dela o que êle queria.

Então todo "filho de santo" escutou. E pai Verequête falou como um príncipe da terra africana que o branco assaltou.

Ele tinha sofrido chicote no tronco mais tarde foi amo criando menino e nunca odiava sabia sofrer. Até nem comia pra dar seu quinhão a quem êle via com fome demais.

"Toiá Verequête!"

"Toiá Verequête!"

E todos vieram pedir sua benção, beijando o rosário de contas e "lágrimas" que a muitos foi dada por Mãe Ambrosina, a "mãe do terreiro". 


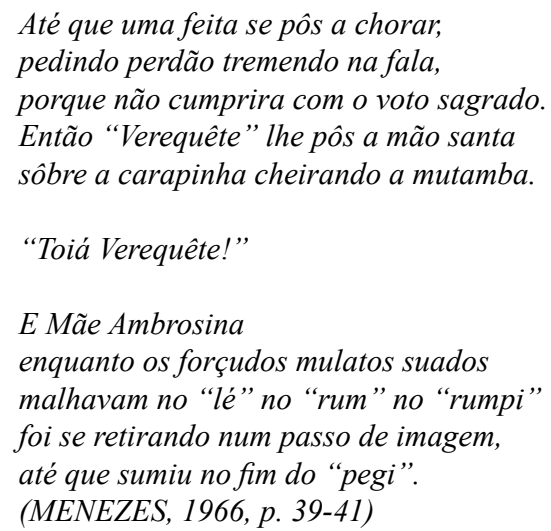

Feita a leitura do poema, é preciso reiterar que nesta abordagem crítica, optamos pela publicação de Batuque feita no ano de 1966. A escolha do livro, deu-se a partir da notável composição poética, aliada ao conjunto de ilustrações de Raimundo Viana, da qual, transpomos o poema de acordo com a ortografia da época, e sem as correções das edições que a sucederam. Assim, dados os devidos esclarecimentos, partiremos para a leitura cuidadosa do Toiá Verequête.

O poema mostra um ritual religioso, provavelmente, o Tambor de mina, culto religioso de matriz africana. A cena é descrita nos versos a partir da perspectiva de alguém que observa a situação, no momento em que ela ocorre. Apesar de se ter um texto em verso, o eu lírico expresso no poema, manifesta-se como um narrador, em fluxo de consciência, caracterizando-o como um poema narrativo. Percebe-se o uso de verbos no pretérito, estes que indicam a sequência narrativa pontuada pelas ações que tem começo, meio e fim. O que ocorre no texto de Menezes está de acordo com as explicações do Narrativa do eu, narrativas do mundo: narrativas do narrar, onde pode-se ler:

\begin{abstract}
A percepção física dos sentidos, bem como impressões, sentimentos e reflexões aparecem misturados à lembrança do passado e este, por sua vez, impregna esses acontecimentos internos tanto quanto se deixa penetrar por eles. Essa condição é comum às narrativas do fluxo de consciência. O passado evocado está de tal modo imbricado nas situações do presente que mesmo as memórias narradas no pretérito perfeito chegam a se confundir com o momento atual (CUNHA, ARAUJO, SILVA, 2016, p.17)
\end{abstract}

No poema citado, ilustra-se a linha tênue que divide o mundo dos vivos das outras manifestações espirituais. Algumas delas podem ser chamadas de possessão ou transe espiritual. Nota-se ainda que, o ritual apresentado faz parte da prática religiosa conhecida, no Brasil, como Tambor de mina. Esse culto religioso surgiu na capital do Maranhão, e se expandiu pelo Pará, Amazonas, outros Estados do Norte e para as capitais que receberam grande número de migrantes do Norte, como Rio de Janeiro e São Paulo. Embora hegemônico no Maranhão, o Tambor de mina - Jeje, Nagô, Cambinda, foi sincretizado em 1996 como manifestação religiosa de origem indígena denominada Cura/Pajelança e com uma tradição religiosa afro-brasileira, surgida em Codó (MA), denominada Mata ou Terecô.

Cada verso descreve a cena que se passa em um terreiro, no momento em que a mulher, Ambrosina, tem o corpo tomado por um espírito, como se diz na linguagem popular, ela recebe um santo. Percebe-se que após o transe espiritual, Ambrosina adquire a voz e trejeitos masculinos. Compreende-se essa mudança da personagem, a partir das explicações de Mundicarmo Ferretti, autor de Tambor de mina e umbanda: O culto aos caboclos no Maranhão, artigo no qual, o estudioso explica que na Mina as entidades masculinas e adultas são mais numerosas e vêm nos toques com maior frequência. Os caboclos, geralmente, só são "donos da cabeça" quando o médium recebe vodum ou gentil, no entanto, na maioria dos terreiros, costumam ser recebidos com maior frequência e permanecer em terra por mais tempo (1996, 
p.3). O aspecto religioso apresentado na explicação sobre o culto em Tambor de mina coincide com a narrativa poética feita por de Bruno de Menezes, que na criação literária, evidencia aspectos culturais da prática religiosa para compor a personificação de Mãe Ambrosina. A expressão literária que corresponde à descrição feita pelo antropólogo, pode ser lida nos versos que seguem:

\section{A voz de Ambrosina em "estado de santo" \\ Virou masculina. \\ O corpo tomou o jeitão de homem mesmo. \\ Pediu um charuto puro da Bahia \\ Depois acendeu soprando fumaça \\ MENEZES, 1966, p.39- grifo do autor)}

O momento de transformação da figura humana, mulher, para o estado de transe, momento místico da ritualização no Tambor de mina, fica ilustrado pela mudança da voz e do comportamento da personagem, conforme ilustra o verso, "O corpo tomou jeitão de homem mesmo". Sobre este fato, explica-se que nas religiões de matriz africana, quando se considera os rituais religiosos de terreiros em várias vertentes, tais como na umbanda, no candomblé e no Tambor de mina, os vocábulos utilizados pelas pessoas que são ou estão "espiritualizadas", em "estado de santo", são recorrentes o uso de uma linguagem corporal e de expressão oral, notadamente, de palavras que remontam uma outra época, mais antiga. E, as palavras usadas são exemplificadas pela maneira de falar de quem as incorpora.

Neste poema, especialmente, a poética narrativa aliada à ilustração de Raimundo Viana e a escrita moderna, adotada por Bruno de Menezes, traduzem de maneira singular nas expressões literárias as pessoas que compõem o cenário moderno, com o uso de temas comuns à periferia e aos negros marginalizados pela sociedade que se instaurava. A ilustração apresenta-se com características próprias e traços fundamentais da religiosidade mística do Tambor de mina, como podemos observar abaixo, na figura 1:

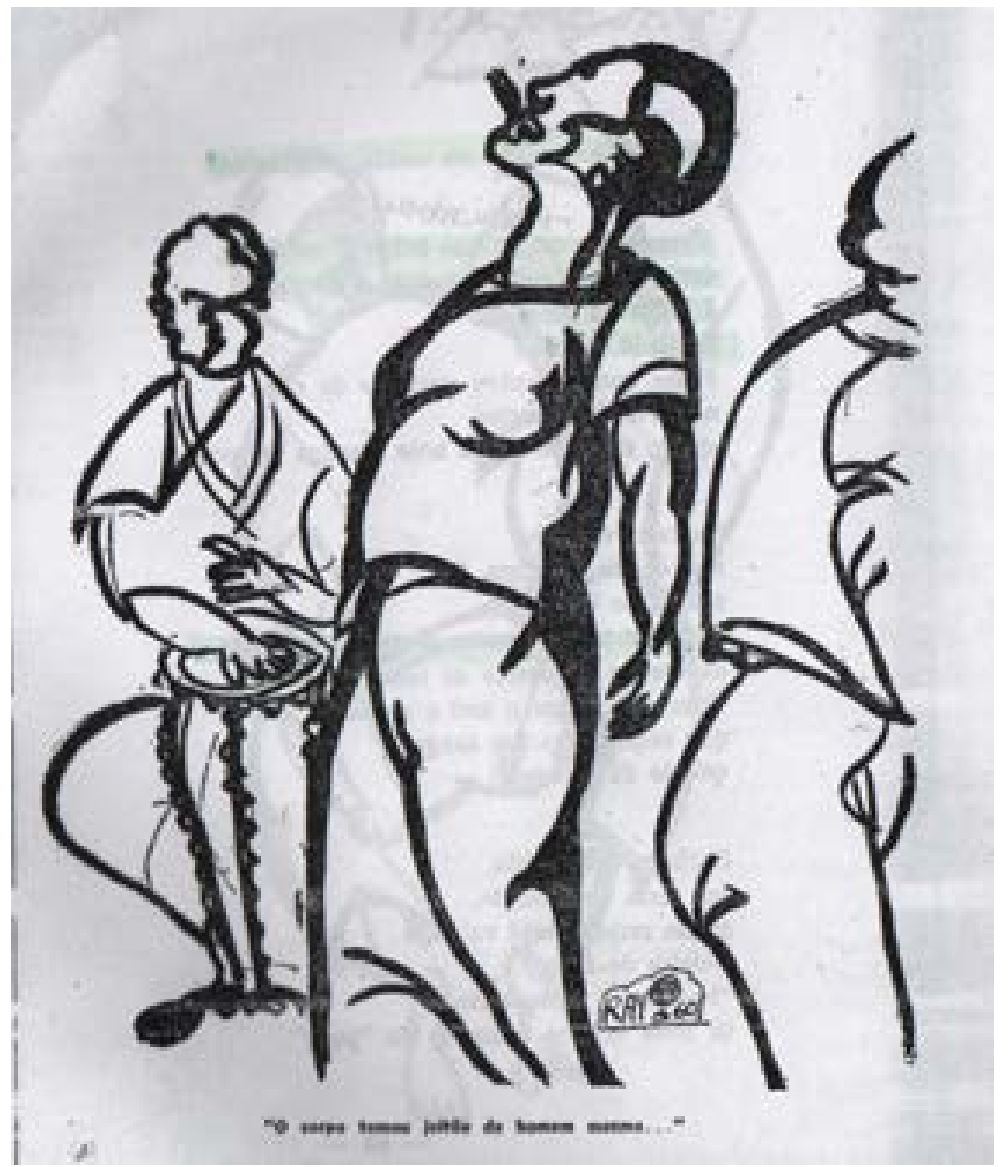

FIGURA 1: VIANA, Raimundo. O corpo tomou jeitão de homem mesmo. Ilustração, 1966. 
Ao observar a ilustração, assim como o conjunto proposto pela a imagem e o poema, nota-se que Ambrosina muda e passa a se chamar Mãe Ambrosina, pois, significa autoridade, uma figura acolhedora, digna de respeito. Além disso, as palavras que representam o léxico do culto religioso são escritas, em destaque pelo autor, com uso de aspas. Entendemos que os sinais de pontuação empregados por Menezes são elementos representativos da linguagem, porém, recortados de outros discursos, alheios à esfera poética, emprestados das práticas rituais de origem africana. Os versos são livres, brancos e trazem palavras escritas em uma linguagem popular, contudo, não tão acessível a todos os leitores, pois, elas têm em seu sentido, um código lexical comum, mas, restrito a um grupo que se forma a partir da religiosidade. São três os vocábulos na segunda estrofe. Nos versos seguintes, estão em destaque: Seus olhos brilharam.

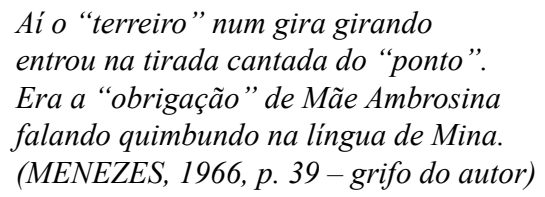

Nesta estrofe, comprova-se que dentre as religiões de matriz africana praticadas no Brasil, a que se refere a temática do poema é o Tambor de mina, pois, no último verso, o eu lírico afirma que Mãe Ambrosina exprimiu-se por meio de outra linguagem, como se pode ler no verso "falando quimbundo na língua de Mina".

Adiante, tem-se a forma exclamativa nos versos:

\section{Toiá Verequête!}

Toiá Verequête!

A ênfase, proporcionada pelo enunciado, ecoa ao longo do poema, por três vezes, como se fosse um refrão. Após o transe espiritual, Mãe Ambrosina muda de condição mais uma vez, e desta feita, ela é personificada por um santo, São Benedito, o santo na matriz cristã, católica, dos homens negros. Vejamos nos versos:

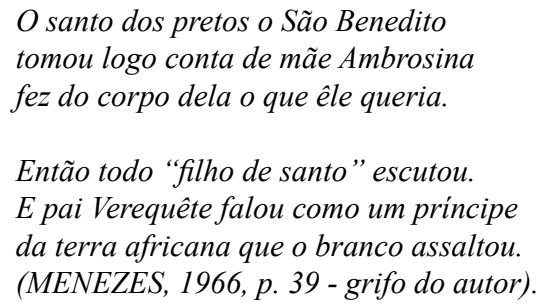

Na quarta estrofe do poema, os filhos de santo são acrescidos como personagens na poética narrativa, pois, figuram com a sua presença no terreiro de Mina. Notamos também que é dado o aspecto simbolista à representatividade de divindades existentes em ambas as religiões. Esse simbolismo conforma os "santos" cristãos em "entidades" nas outras religiões. A título de exemplo, citamos o caso de Nossa Senhora da Conceição, santa existente no cristianismo católico e que é chamada de Iemanjá em outros cultos. Sabe-se que a figura simbólica é a mesma, contudo, ela recebe um nome em cada religião. No caso do poema, o santo, São Benedito, torna-se pai Verequête. Na estrofe citada, de maneira subliminar, há ao final dos versos a denúncia em relação à exploração das terras africanas, e pai Verequête é comparado a um príncipe.

Na sequência da leitura do texto, percebemos a reflexão e o estado de resiliência do homem negro, ilustrado em pai Verequête: "[...] tinha sofrido chicote no tronco"; mas, permanecia bondoso e alimentava aos que sentiam fome, assim como ele, mostrando-se forte, resignado e superior aos maus tratos. Dessa forma, pensamos que se a literatura nos serve além da fruição da arte, ainda, para a compreensão da sociedade e de uma época, podemos aliar os versos de Menezes à reflexão feita 
por Darcy Ribeiro sobre a condição do negro, antes escravo, e que mesmo livre não teve acesso a outras oportunidades, devido sua condição histórica. Ei-la:

\begin{abstract}
Liberto, porém, já não sendo de ninguém, se encontrava só e hostilizado, contando apenas com sua força de trabalho, num mundo em que a terra e tudo o mais continuava apropriada. Tinha de sujeitar-se, assim, a uma exploração que não era maior que dantes, porque isso seria impraticável, mas era agora absolutamente desinteressada do seu destino. Nessas condições, o negro forro, que alcançara de algum modo certo vigor físico, poderia, só por isso, sendo mais apreciado como trabalhador, fixar-se nalguma fazenda, ali podendo viver e reproduzir. O débil, o enfermo, o precocemente envelhecido no trabalho, era simplesmente enxotado como coisa imprestável. (1995, p. 232).
\end{abstract}

Os maus tratos e todas as outras formas de subjulgamento sofrido pelos negros serviram, de certa forma, para torná-los resistentes não apenas em aspectos físicos, mas para os que vivem e sobrevivem até os dias de hoje, após a abolição da escravatura. A denúncia, apontada pelo poeta Bruno de Menezes, antecipa na cena moderna da Amazônia, questões que serviram como fonte de debate e na luta do movimento da negritude, no Brasil e no mundo.

Na sexta estrofe, tem-se o duplo representando no poema por Mãe Ambrosina e pai Verequête. Eles se apresentam na fala e no comportamento de um mesmo personagem, no ato de dar a benção e no gesto de perdão. Neste trecho do poema, podemos observar que as religiões, muitas vezes, compartilham não somente as figuras de santos e entidades que simbolicamente se representam. Há, também, algumas práticas que são feitas, em cultos católicos cristãos e em outros cultos religiosos. $\mathrm{Na}$ composição poética, o ato de dar a benção é um deles, como registrado no verso "E todos vieram pedir a sua benção". Esse gesto pode ser reconhecido como uma manifestação de fé, e é recorrente e compartilhado por várias religiões. O significado da benção pode estar aliado ao respeito, a resignação, ou mesmo, uma expressão de agradecimento.

$\mathrm{Na}$ parte final do poema, encontramos o lamento, o pedido de perdão de uma feita que não cumprira com as suas promessas: "Até que uma 'feita' se pôs a chorar/ Pedindo perdão tremendo na fala / Porque não cumprira com o voto sagrado/ Então "Verequête" lhe pôs a mão santa/ Sobre a carapinha cheirando a mutamba"2. Além do lamento, a sinestesia do último verso da estrofe, remete-nos ao odor de uma árvore, provavelmente, um elemento que serviu de preparo para o ritual de terreiro, liderado pela figura marcante de Mãe Ambrosina. A fusão das imagens, na poética, sugere ainda, por meio dos versos seguintes, o encerramento do ritual religioso:

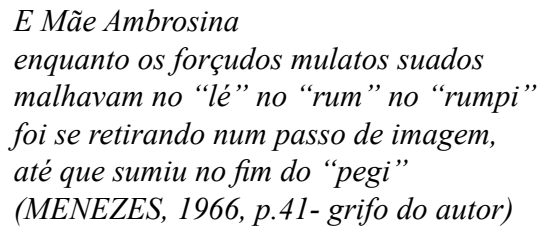

Novamente, as palavras que pertencem ao léxico do Tambor de mina aparecem registradas entre aspas, e acrescenta-se que na edição escolhida, a de 1966, não há notas explicativas sobre elas, tão pouco seus significados. Conclui-se assim que, os significados cabem ao leitor e que na produção de Bruno de Menezes, o léxico, a pontuação, o registro da expressão oral são recursos da linguagem poética, e os sentidos devem ser desvelados pelos leitores, assim como os aspectos culturais, religiosos e da região amazônica, sempre ilustrando o cenário cotidiano, sobretudo dos negros.

\section{CONSIDERAÇÕES FINAIS}

Com estas observações, nada finais, sobre a leitura feita pela ótica dos es-

tudos culturais e da antropologia, anotamos que a obra de Bruno de Menezes com-
2 [Bot.]- Mutamba ou camacã é o nome de uma árvore de médio porte, nativa da América do Sul, da família das Esterculiáceas. Produz flores amarelas e frutos redondos, de cor escura, com saliências, cujas sementes são comestíveis e têm propriedades medicinais. Suas folhas são usadas na alimentação do gado. Da sua casca se extrai fibras usadas na confecção de cordas e objetos artesanais. Também é conhecida como mutambo, cambacã, embira, envireira, mucungo, pojó, guazuma. No caso empregado, a planta alude ao forte perfume exalado, da qual são extraídos óleos para cabelo.

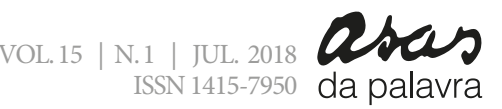


põe, de fato, a cena moderna brasileira com grandiosidade. Apenas neste texto, no qual vimos, uma pequena parte desta produção poética, pode-se observar aspectos da cultura popular, da religiosidade e da expressão artística, sobretudo, do homem negro. Podemos afirmar, categoricamente, que ler a obra de Menezes é caminhar pela escrita moderna sob o perspectivismo de um autor da/na Amazônia. Além disso, o leitor pode visualizar, imaginar, recriar pontos essenciais das manifestações do povo, da rua, da linguagem por meio da expressão poética, que como se leu neste artigo, apresenta-se também como narrativa.

Retomamos assim, o que foi escrito no livro Batuque na $7^{\text {a }}$ edição, publicada em 2005, na qual, encontramos o prefácio escrito por Josse Fares e Paulo Nunes e reiteramos a necessidade de assinalar o poeta Bruno de Menezes não apenas como um integrante fundamental da expressão lírica da Amazônia, mas, fazer notá-lo no contexto da negritude de expressão brasileira.

A tese de doutorado que norteia este artigo ratifica a importância desse autor para a literatura nacional, assim como, o aprofundamento desta escrita com as proposições do movimento da negritude. Bruno de Menezes e Léopold Sédar Senghor são líderes da negritude no mundo. Eles têm muitos pontos em comum em suas criações artísticas e ambos desvelam a cultura, a cor local e a identidade que são usadas como fonte de inspiração crítica e de poeticidade. A enunciação é posta como um elemento catalisador de ações que transformam a cena, o lugar da poesia, em imagem. A figura de linguagem recorrente, a sinestesia, provoca um cruzamento de sensações, como pode ser lido no verso "enquanto os forçudos mulatos suados", por meio da associação de palavras sonoramente afins. Elas criam expressões na combinação de sensações diferentes para provocar, assim, uma só impressão.

A negritude, no Brasil, está exemplarmente representada pelo poeta. A religiosidade e a cultura afro-brasileira expandem-se através da literariedade da escrita singular, moderna e derivada do olhar sagaz de um escritor, ou melhor, um mestre da cultura popular.

\section{REFERÊNCIAS}

BERTRAND, Denis. Caminhos da semiótica literária. Bauru/SP: EDUSC, 2003.

BOSI, Alfredo. O ser e o tempo da poesia. $8^{\mathrm{a}}$ ed. Companhia das Letras. São Paulo, 2010.

CUNHA, Betina Ribeiro Rodrigues da. ARAÚJO, Marcio de Melo. COSTA E SILVA, Natali Fabiana da. (Orgs.) (2016). Narrativa do eu, narrativas do mundo: narrativas do narrar. Macapá: UNIFAP; Rio de Janeiro: Autografia.

FERRETTI, Mundicarmo. Tambor de Mina e Umbanda: O culto aos caboclos no Maranhão. In: Jornal do CEUCAB-RS: O Triangulo Sagrado, Ano III, n. 39 (1996), 40 e 41 (1997). Disponível em $<<$ http//:www.geocities.com/Augusta/1531/tambor.htm. $>>$. Acesso em 27. ago. 2016.

LOWY, Michael. A filosofia da história de Walter Benjamin. In: Estudos avançados 16. Disponível em: http://www.scielo.br/pdf/ea/v16n45/v16n45a13.pdf. Acesso em 10. dez. 2010.

MENEZES, Bruno. Batuque: Poemas. 5ª Ed. Belém-Pará: Família Bruno de Menezes, 1966. Batuque: Poemas. $6^{\text {a }}$ Ed. Belém-Pará: Secretaria de Cultura, 1984.

PACHECO, Terezinha de Jesus Dias. Bruno de Menezes e o Modernismo no Pará. In: Em tese. Belo Horizonte, v. 6, p. 165-172, ago. 2003. Disponível em $<<$ http://www.periodicos.letras. ufmg.br/index.php/emtese/article/viewFile/3551/3511 >>. Acesso em: 12 maio 2018.

RIBEIRO, Darcy. O povo brasileiro: a formação e o sentido do Brasil. 2 ed. São Paulo: Companhia das Letras, 1995. 
REVISTA DO CURSO DE GRADUAČ̃O EM LETRAS E DO PROGRAMA DE PÓS-GRADUACÃO EM COMUNICAC̃̃O, LINGUAGENS E CULTURA DA UNIVERSIDADE DA AMAZÔNIA

digma. In: Africana Studia, no 04, 2001. Edição da Faculdade de Letras do Porto. p. 149-162.

Disponível em << http://www.africanos.eu/ceaup/uploads/AS04_149.pdf $>>$. Acesso em : 20 abr. 2018

SENGHOR, Léopold Sédar. Oeuvre poétique.Paris: Éditions du Seuil, 1990.

\section{Recebido em 21 Mai 2018 | Aprovado em 12 Jul 2018}

Mariana Janaina dos Santos ALVES

Doutoranda em Estudos Literários na Universidade Estadual Paulista "Júlio de Mesquita Filho" - UNESP, FCL-Car. Professora de língua e literatura francesa na Universidade Federal do Amapá - UNIFAP - Campus Binacional de Oiapoque. Membro do Núcleo de Pesquisa em Estudos Literários NUPEL - vinculado ao CNPq. E-mail: marianaalves@unifap.br. Currículo lattes: http://lattes.cnpq.br/9757403266022290. 